\title{
Acute chest syndrome in sickle cell disease/HBE patient, A case report
}

\author{
Ibrahim Khamees ${ }^{1}$, mohamed yassin ${ }^{2}$, and Waail Rozi ${ }^{3}$ \\ ${ }^{1}$ Affiliation not available \\ ${ }^{2} \mathrm{HMC}$ NCCCR \\ ${ }^{3}$ Hamad Medical Corporation
}

January 25, 2021

\begin{abstract}
Hemoglobin S (HBS) and hemoglobin E (HBE) are common hemoglobinopathies, but combined heterozygosity of HBS and HBE (HBSE) is relatively a rare disease. Most reports suggest that HBSE is generally benign condition. In this report we describe a 17-year-old male patient presenting with acute chest syndrome treated with exchange transfusion.

Acute chest syndrome in sickle cell disease/HBE patient, A case report

Ibrahim Khamees ${ }^{\mathrm{a}}$, Waail Rozi ${ }^{\mathrm{a}}$, Mohamed A Yassin ${ }^{\mathrm{b}}$

a Department of Internal medicine, Hamad Medical Corporation, Doha/Qatar.

b Department of Medical Oncology/ Hematology Section. Hamad Medical Corporation. Doha/Qatar

Corresponding author:

D. Ibrahim Khamees, Department of Internal Medicine Hamad Medical Corporation, Doha/Qatar. PO BOX 3050 Ibrahim_khamees@hotmail.com +974 55169599 D. Waail Rozi, Department of Internal Medicine Hamad Medical Corporation, Doha/Qatar. PO BOX 3050 Waail.rozi@gmail.com +974 50041728 D. Mohamed A Yassin Department of Internal Medicine Hamad Medical Corporation, Doha/Qatar. PO BOX 3050 yassinmoha@gmail.com +97455037393
\end{abstract}

Key words: sickle cell disease, hemoglobin S, hemoglobin E, HBSE, acute chest syndrome

Key clinical message: The presented case will shed some light on one of the rarest complications of HBSE disease which is acute chest syndrome, and will highlight the management of that complication.

Abstract

Hemoglobin S (HBS) and hemoglobin E (HBE) are common hemoglobinopathies, but combined heterozygosity of HBS and HBE (HBSE) is relatively a rare disease. Most reports suggest that HBSE is generally benign condition with few reported complications like vaso-occlusive crises, acute chest syndrome and bone necrosis. In this report we describe a 17-year-old male patient presenting with acute chest syndrome treated with exchange transfusion.

Introduction

HBS, which is the hemoglobin type responsible for sickle cell disease, is localized mostly in Africa, India and some parts of the Middle East [1]. In sickle cell disease, there is homozygosity of HBS mutation, and in stressful conditions like infections hemoglobin will be deoxygenated and HBS will polymerize in the 
vessels, leading to multiple complications including vaso-occlusive pain and acute chest syndrome [2]. HBE is found mostly in Southeast Asia. Patients who are homozygous for HBE generally have mild anemia and are clinically asymptomatic, whereas individuals who are heterozygotes for HBE and Beta thalassemia for example have a variable clinical spectrum ranging from mild to very severe disease requiring regular blood transfusion [3]. Due to increasing rate of migrations and marriages happening between different races, Increasing numbers of patients with compound heterozygosity for HBS and HBE are found worldwide, and scarce data about the disease and the complications related to it have been reported.

Acute chest syndrome is considered the most common cause of death in sickle cell disease patients. It is defined by the presence of new radiographic pulmonary infiltrates as well as fever and respiratory symptoms. Management ranges from pain control and fluid replacement in mild disease to simple transfusion or exchange transfusion in more severe presentations [4]. Acute chest syndrome mostly occurs in Patients who are homozygous for HBS, however there are few reported cases of acute chest syndrome happening in patients with HBSE disease $[5,6]$.

Case report

A 17-year-old male patient who is known to have HBSE disease, presented with a history of chest and back pain for few days prior to admission. He also complained of non-productive cough for 2 days but denied fever. On examination, his heart rate was 110 and his respiratory rate was around 25 with normal temperature of 36.9. On chest exam, he had left basal crackles with decreased air entry.

Initial laboratory investigations are mentioned in table 1.

Table 1: laboratory investigations

His chest xray showed left retrocardiac and left lower lung zone opacity suggesting left lower lobe consolidation, shown in (Figure 1)

Figure 1: chest x-ray

The patient was diagnosed to have community acquired pneumonia and started on ceftriaxone $1000 \mathrm{mg}$ daily for seven days and azithromycin $500 \mathrm{mg}$ daily for three days as inpatient. The patient did not improve and started requiring oxygen two days after admission, he became more tachypneic and tachycardiac so he was shifted to the medical intensive care unit and started on non-invasive ventilation, COVID-19 and all cultures were negative. Hematology recommended to do hemoglobin electrophoresis for the patient considering the possibility of acute chest syndrome. Hemoglobin electrophoresis was done and it showed the findings in table 2 .

Table 2: Hemoglobin electrophoresis

The patient underwent a session of exchange transfusion, then during the following days the patient improved gradually and was discharged from the hospital 4 days after the exchange transfusion. He was commenced on folic acid $5 \mathrm{mg}$ daily and hydroxyurea $500 \mathrm{mg}$ twice a day as a prophylaxis, with close follow up in hematology clinics.

Discussion

HBS molecule is a result of the replacement of the hydrophilic glutamic acid by the hydrophobic valine residue at position 6 in the beta globin chain. This mutation results in the sickle shape of the affected hemoglobin molecule, which changes to that shape when deoxygenated in certain situations like infections [7]. This process can causes several acute complications like acute vaso-occlusive pain, acute chest syndrome, stroke and priapism $[8,9]$. Sickle cell disease can result in some chronic complications as well, for example it can cause chronic anemia, chronic bone pain and avascular necrosis [10].

HBSE disease is considered a benign condition in general. However, David Masiello et al., in their review described 26 patients with HBSE heterozygosity, 9 of them had clear complications attributed to sickling ranging from acute painful episodes to splenic thrombosis and acute chest syndrome, all of these patients were 
above 20 year-old. They suggested also that patients with HBSE disease should be followed and managed in the same way like patients with $\mathrm{Hb} \mathrm{S} / \mathrm{b} 1^{+}$thalassemia [11].

Sickling associated complications in HBSE disease are thought to occur more commonly in people aged more than 20, but some reports described young patients with this disease who had severe complications as well. A review done in turkey (An area with a high rate of consanguinity) reported 20 patients with HBSE disease, two of them had mild vaso-occlusive crises and one who was diagnosed with the disease at age of 11 and was started on hydroxyurea, suffered from cerebrovascular stroke later on [12]. Another case report described a young girl who was diagnosed with HBSE disease at the age of 5 due to leg pain, where the images suggested bone infarction. At the age of 7 she had a fatal massive bone marrow embolism [13].

Acute chest syndrome is uncommon to happen in patients with HBSE disease. Upon reviewing the literature, we found 5 cases of HBSE disease complicated by acute chest syndrome $[5,6,14,15,16]$. In one case report, a 66 year-old patient with HBSE disease suffered from bone infarction and acute chest syndrome which improved with simple blood transfusion of 2 units along with supportive care and was discharged on hydroxyurea [5]. Another case report presented a 22 year-old patient with HBSE disease diagnosed with parvovirus B19 infection and acute chest syndrome, also received simple blood transfusion and improved [6]. A third paper described a 24 year-old patient with HBSE disease admitted with acute chest syndrome and managed with supportive therapy only [16]. Our patient was admitted with acute chest syndrome which did not resolve with antibiotics, and required exchange transfusion, after which the patient improved significantly and was discharged on hydroxyurea.

Conclusion

HBSE disease is thought to be a benign condition, but more and more reports are being published describe complicated HBSE disease. Increased number of cases of HBSE disease is expected with the increasing rate of migrations and interracial marriages. This warrants early follow up of such patients and early recognition and management of the complications of this disease especially the severe ones like acute chest syndrome.

Statement:

Acknowledgment:

Authors would like to acknowledge the internal medicine and hematology departments at Hamad Medical Corporation for supporting this publication.

Statement of ethics:

Written informed consent was obtained from the patient to allow the publication of information including images.

Case approved by HMC Medical Research Center.

Disclosure Statement:

The authors report no conflicts of interest in this work.

Funding sources

Qatar National Library.

Author's contribution:

All authors contributed equally in writing and editing.

References

1- Piel FB, Patil AP, Howes RE, Nyangiri OA, Gething PW, Williams TN, Weatherall DJ, Hay SI. Global distribution of the sickle cell gene and geographical confirmation of the malaria hypothesis. Nat Commun 1, 104. 
2- Rees DC, Williams TN, Gladwin MT. Sickle-cell disease. The Lancet. 2010 Dec 11;376(9757):2018-31.

3- Fucharoen S, Weatherall DJ. The hemoglobin E thalassemias. Cold Spring Harbor perspectives in medicine. 2012 Aug 1;2(8):a011734.

4- Farooq S, Abu Omar M, Salzman GA. Acute chest syndrome in sickle cell disease. Hospital Practice. 2018 May 27;46(3):144-51.

5- Tay SH, Teng GG, Poon M, Lee VK, Lim AY. A case of hemoglobin SE presenting with sickle cell crisis: case report and histological correlation. Annals of the Academy of Medicine, Singapore. 2011 Dec 1;40(12):552-3.

6- Eichhorn RF, Buurke EJ, Blok P, Berends MJ, Jansen CL. Sickle cell-like crisis and bone marrow necrosis associated with parvovirus B19 infection and heterozygosity for haemoglobins S and E. Journal of internal medicine. 1999 Jan;245(1):103-6.

7- Malowany JI, Butany J. Pathology of sickle cell disease. InSeminars in diagnostic pathology 2012 Feb 1 (Vol. 29, No. 1, pp. 49-55). WB Saunders.

8- Wali Y, Kini V, Yassin MA. Distribution of sickle cell disease and assessment of risk factors based on transcranial Doppler values in the Gulf region. Hematology. 2020 Jan 1;25(1):55-62.

9- Adeyoju AB, Olujohungbe AB, Morris J, Yardumian A, Bareford D, Akenova A, Akinyanju O, Cinkotai K, O'reilly PH. Priapism in sickle-cell disease; incidence, risk factors and complications-an international multicentre study. BJU international. 2002 Dec;90(9):898-902.

10- Shier A, Abdelrazek M, Soliman A, De Sanctis V, Elsayed A, Abdulla M, Mohamed S, Yassin K, Bilal I, Yassin M. Short-Term Outcome and MRI Changes in Three Adult Patients with Sickle Cell Disease and Aseptic Osteonecrosis after Treatment with Hyperbaric Oxygen Therapy: A Preliminary Report. Case Reports in Oncology. 2020;13(1):365-72.

11- Masiello D, Heeney MM, Adewoye AH, Eung SH, Luo HY, Steinberg MH, Chui DH. Hemoglobin SE disease - a concise review. American journal of hematology. 2007 Jul;82(7):643-9.

12- Acipayam C, Oktay G, Ilhan G, Çürük MA. Hemoglobin SE disease in Hatay, in the southern part of Turkey. Thalassemia Reports. 2015 Feb 25.

13- Rayburg M, Kalinyak KA, Towbin AJ, Baker PB, Joiner CH. Fatal bone marrow embolism in a child with hemoglobin SE disease. American journal of hematology. 2010 Mar;85(3):182-4.

14- George E, Iqbal QM. Hb ES presenting as avascular necrosis. The Southeast Asian journal of tropical medicine and public health. 1978 Dec;9(4):568.

15- ENGELSTAD BL. Functional asplenia in hemoglobin SE disease. Clinical nuclear medicine. 1982 Mar $1 ; 7(3): 100-2$.

16- Knox-Macaulay HH, Ahmed MM, Gravell D, Al-Kindi S, Ganesh A. Sickle cell-haemoglobin E (HbSE) compound heterozygosity: a clinical and haematological study. International journal of laboratory hematology. 2007 Aug;29(4):292-301.

Figure legends:

Table 1: laboratory investigations

Figure 1: chest x-ray

Table 2: Hemoglobin electrophoresis

Hosted file 
HBSE table 1.pdf available at https://authorea.com/users/390591/articles/505675-acute-chestsyndrome-in-sickle-cell-disease-hbe-patient-a-case-report

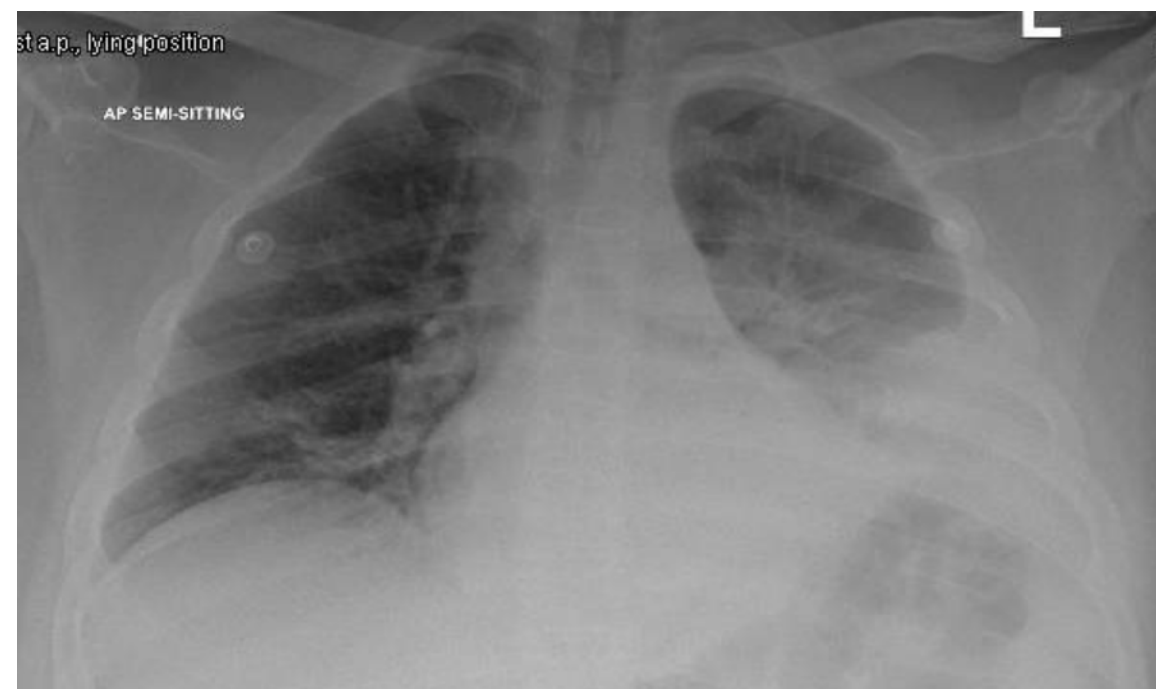

\section{Hosted file}

HBSE table 2.pdf available at https://authorea.com/users/390591/articles/505675-acute-chestsyndrome-in-sickle-cell-disease-hbe-patient-a-case-report 